\title{
Fteknokultura
}

\#Mena, R.A. y Basall, A. (2016). Bloggers latinoamericanos, creativos culturales de inicios del siglo XXI, Revista Teknokultura Vol. 13(1), 55-78.

Recibido: $\quad$ 01-02-2016

Aceptado: 29-04-2016
Open peer review

http://revistas.ucm.es/index.php/TEKN/pages/view/opr-51781

\section{Bloggers latinoamericanos, creativos culturales de inicios del siglo XXI}

\section{Latin American bloggers, the cultural creatives at the dawn of the 21st century}

\author{
Ramón A. Mena y Alain Basail \\ El Colegio de la Frontera Sur \\ Universidad de Ciencias y Artes de Chiapas \\ rmenadecosur.mx \\ alain.basail@unicach.mx
}

\section{Resumen}

El presente artículo tiene como objetivo explorar la producción textual, la identidad blog y las prácticas sociales a partir de la sistematización de relatos escritos por bloggers latinoamericanos desde una perspectiva de la fenomenología tecnológica. Planteamos una discusión sobre la comprensión de prácticas sociotécnicas y significados de las experiencias humanas que bloggers latinoamericanos debaten a partir de sus posicionamientos políticos, económicos, éticos, sociales y culturales. Son "creativos culturales" del siglo XXI, debido a 
que escriben desde sus contextos, reflexionan las experiencias y cotidianidades de sus sociedades desde la red como ejercicio para la comprender el presente de Latinoamericana y su lugar en el mundo global.

El presente artículo tiene como objetivo explorar la producción textual, la identidad blog y las prácticas sociales a partir de la sistematización de relatos escritos por bloggers latinoamericanos desde una perspectiva de la fenomenología tecnológica

\section{Palabras Clave}

Tecnología; ciencias sociales y humanidades; cultura; fenomenología; blogs.

\section{Abstract}

This article explores the textual production, blog identities and social practices about the systematization of stories written by Latin American bloggers from a technological perspective and phenomenology. We analyse the socio-technical practices and meanings of Latin American bloggers and their approaches to political, economic, ethical, social and cultural issues. They are the "cultural creatives" of the century XXI because they write from their contexts, reflecting the experiences and everyday life of their networked societies as an exercise for understanding the Latin American present and its place in the global world.

\section{KEYWORDS}

Technology; social sciences and humanities; culture; phenomenology; blogs. 


\section{Contenidos}

1. Introducción

2. Revisión Literaria. Una epistemología para comprender a la red

3. Metodología. Internet, un reto metodológico para la fenomenología tecnológica

4. Resultados

5. Conclusiones

6. Referencias

\section{Contents}

1. Introduction

2. Bibliographic review. An epistemology to understand networks

3. Methodology. Internet, a technological methodological challenge for phenomenology

4. Results

5. Conclusions

6. References 



\section{Introducción}

La tradición de los estudios sobre la comunicación mediada por tecnología hace una profunda reflexión sobre los medios electrónicos desde finales de 1990 hasta la actualidad. La reflexión que se ofrece desde Latinoamérica destaca el proceso de actualización de medios de información convencionales que dominaron el discurso y el pensamiento de las naciones de la región en todo el siglo XX. Observamos el declive de los diarios impresos, la radio, la televisión y el nacimiento de un nuevo dominio encabezado por las redes sociales en un inusitado acceso social por medio de dispositivos móviles, la mundialización de la información y emergencia de la comunicación electrónica. Presenciamos un sinnúmero de relaciones sociotécnicas entendidas como un entramado de elementos económicos, políticos y socioculturales. Asimismo, somete a la comunicación impresa, radial y televisiva a procesos de actualización de sus lenguajes y estilos no exentos de tensiones en la medida que permiten vincular un conjunto de capacidades de resolución de problemas sistémicos, como el cambio, la actualización y la innovación tecnológica. Observar estas relaciones, como señala Thomas (2009, p. 41), implica superar “...las limitaciones de concepciones lineales en términos de transferencia y difusión, mediante las dinámicas de integración en sistemas sociotécnicos, y procesos de re-significación de tecnologías".

En la red de internet se sitúa un orden social sorprendentemente nuevo y poco explicado. A diario millones de latinoamericanos viven experiencias de interacción con las que logran satisfacer el impulso de poner "un pie en la red", participando participar con su opinión en el vasto mundo de las ideas, la comunicación y la interacción en los medios masivos, hasta ahora vetado y exclusivamente controlado por los grandes grupos editoriales, los conglomerados de medios de comunicación y el propio Estado.

Como respuesta destacan los posicionamientos de los bloggers latinoamericanos como "creativos culturales" del siglo XXI, ${ }^{1}$ que construyen discursos críticos ante el embate de sistemas políticos y económicos, las disputas por recursos naturales, el papel de la mujer, la apertura multicultural; fenómenos todos que se materializan en un complejo sistema de vida a escala variable personal, familiar, comunitaria, regional, nacional y trasnacional.

\footnotetext{
${ }^{1}$ Giménez (2015) define como creativos culturales a las personas que pertenecen a una franja cultural definida en Estados Unidos, cuyos integrantes comparten una "serie de valores y actitudes que conforman una nueva visión del mundo y dan origen a un nuevo estilo cultural en donde se destaca la apertura a una implicación societa ria y al desarrollo personal" (p. 144).
} 


\section{Revisión Literaria. Una epistemología para comprender la red}

Los primeros blogs aparecieron en el año 2000 como una página electrónica personal. Hoy apenas sobreviven como un espacio de expresión y comunicación independiente. En los portales se experimentó la transición del formato textual entre los medios impresos a digitales. Los autores o editores desarrollaron habilidades y técnicas para el manejo masivo de información, réplicas y contra replicas que generaban. Por su fácil acceso y desenfadado uso se constituyeron rápidamente en una asequible opción de participación para los editorialistas y líderes de opinión pública.

En la actualidad el blog no es el espacio con mayor popularidad y uso, sin embargo sigue manteniendo sus interfaces para la auto-publicación, gestión en la administración y conexión con las redes sociales. En la actualidad se constituyen como uno de los paisajes tecnológicos ${ }^{2}$ más antiguos en la actividad web. No obstante algunos analistas como Anjewierden et al. (2004), Cayzer (2004), Nardi (2004), Schittine (2004), Wrede (2004), Hsu et al. (2008) y Sullivan (2010) consideran que es un espacio con características únicas que lo hace ser el preferido en la red, a pesar de las notables actualizaciones y modalidades de comunicación en otros ambientes. Hoy en día, una parte significativa de la experiencia digital latinoamericana es relatada en los blogs. Manuel Castells, reflexionó al respecto en su trilogía La Era de la Información, El poder de la Identidad y Fin de Milenio, editados en 1999, y prevenía de un periodo caracterizado por la transición de un real cambio social en la sociedad red, promovido por una revolución tecnológica centrada en las tecnologías digitales de información y comunicación. De igual manera los estudios anuales de la que, desde 2001 hasta la fecha, hace la Asociación Mexicana de Internet, muestran la existencia de colectivos o individuos que necesitarían reflexionar sobre los hábitos en internet, el comercio electrónico, las nuevas tecnologías $\mathrm{y}$, entre otros aspectos,, la protección de datos personales, entre otros.

Todo lo anterior lo podemos analizar y comprender desde los marcos teóricos ofrecidos por la fenomenología y la etnometodología debido a que aspiran a la comprensión de los efectos que tienen la tecnología, la ciencia y la comunicación, en diferentes ámbitos y mo-

\footnotetext{
${ }^{2}$ Se entiende por paisaje tecnológico un ambiente social, temporal y dimensional donde los usuarios intercambien experiencias, se capacitan y conocen de primera mano las nuevas tecnologías de la información y la comunicación. El paisaje tecnológico debe estar acompañado de una serie de soportes que le permitan estar calificando su existencia, tales como las diversas organizaciones originadas por los órganos reguladores del uso de internet, la iniciativa privada o ciudadana, que crean "estadísticas en materia de sociedad de la información" y proponen "normatividades de calidad y mejoras prácticas en el desempeño de la red".
} 
mentos del desarrollo tecnológico de la humanidad. Scott Lash (2005) en su libro Crítica de la Información en donde analiza los principios estructurales de la cultura global de la información respecto de la sociedad industrial y estudia los bienes de consumo (objetos) mientras se mueven con velocidad a través de las redes globales. A diferencia de las antiguas estructuras sociales del orden industrial, el nuevo orden mundial de la información favorece la aparición de objetos autónomos. Los objetos o artefactos son autónomos porque escapan al control de los sujetos a través de las redes globales constituyéndose en flujos (signos, medios, migrantes, tecnología, dinero). De esta manera, los objetos pasan a compartir cualidades informacionales.

Lash (2005) sitúa el cambio de una cultura representacional a una cultura tecnológica donde el dualismo sujeto-objeto es remplazado por una dimensión inmanente a la sociedad y requiere de la reflexividad como vínculo entre el conocimiento y la acción. Garfinkel (2006) se inclina por una fenomenología radical de las comunicaciones en la que lo intangible y lo material se "comprimen" en una única unidad comunicacional. Lo anterior implica que pasemos del observador, que puede prestar o no atención a las cosas, produce conocimiento del objeto por medio de juicios y la duda, y conoce en términos de causa y efectos, a un experimentador, que conoce gracias a una actitud en la perspectiva de su intencionalidad, en menos causal que descriptivo, que no explica sino interpreta y que basa su conocimiento a través de la experiencia.

Lash (2005) y Garfinkel (2006) proponen un camino que va de la actitud natural (el plano empírico), pasando por una actitud científica (una forma de ver al mundo que se observa desde otro mundo, manifestándose como atemporal e inextensa) a una actitud reflexiva, que propone que la descripción no produce un conocimiento a priori sino que es demostrativo, convincente o apodíctico, que es el conocimiento de las cosas en sí. De tal forma Lash propone que la etnometodología resuelva el qué pero sobretodo el cómo. Responder el qué es la interpretación y descripción fenomenológica de cosas y acontecimientos a partir de ámbitos que son las actitudes. En tanto responder el cómo es en sí un modo de alcanzar el conocimiento, realizado por descripciones empíricas, en donde el conocimiento es socialmente organizado y práctico.

Para hablar de una fenomenología empírica de las comunicaciones Garfinkel (2006) señala que se: “...responde a qué es lo reflexivo, siendo esto las 'prácticas descriptivas' dadas en la colectividad, en donde se le da congruencia a la realidad, y en donde 'el contar' da su carácter central de las comunicaciones” (p. 65). El cumplimiento de las prácticas descriptivas (comentarios) asegura la reproducción de las actividades y disputas por sentidos y significados. Por tanto los comentarios en las conversaciones y el cómo de las mismas son 
considerados como actividades extendidas en el tiempo, en donde no solo están "ahí" sino constantemente "ahora".

\section{Metodología. Internet, un reto metodológico para la fenomenología tecnológica}

La delimitación metodológica para este escrito consistió en seleccionar al blog como el paisaje virtual que aglutinará a un colectivo virtual estable, temáticamente coherente y localizable a partir de narrativas históricamente situadas, y autores que se identifican, reconocen y reflexionan su quehacer dentro y fuera de la red. En el blogger reconocemos a personas que podemos denominar como creadores culturales por introducir, mantener y compartir una cultura común en materia digital aportando coherencias discursivas al aparente caos de información e inmediatez de algunas secciones de la red. La reflexión metodológica de este trabajo se estructura en torno a las siguientes preguntas: ¿cómo explorar la producción textual, la identidad blog y las prácticas sociales a partir de la sistematización de relatos escritos de bloggers latinoamericanos?¿Qué tipo de análisis podemos realizar de la experiencia sociotécnica de una muestra de bloggers que compartieron sus relatos de vida?¿Cómo comprender las cualidades emergentes de las interacciones virtuales a partir de la reflexividad en las experiencias en la red de internet?

Las prácticas digitales de los usuarios en Latinoamérica inician en el acceso cotidiano a dispositivos tecnológicos desde donde suben su experiencias videograbada en YouTube, buscar "likes" en comunidades como Facebook o popularizar algún tema en Twitter. Pero no terminan en el uso banal de la experiencia digital. Destacamos los argumentos que manejan los propios bloggers para dotar de significados sociotécnicos a su vida. Los fenómenos contemporáneos en la red no se reducen al tráfico masivo de los "bots" o "robots fantasmas" que colman la red de contenido sin sentido, falsa popularidad y descredito a partir de perfiles inexistentes que causan caos discursivo provocando desconfianza en los lectores en la red. Las características de una identidad blogger, supone reconocer la experiencia sistemática y documentada de una identidad de tránsito entre las convencionales formas de comunicación electrónica (periodismo gráfico, radiofónico y televisivo) y las formas indómitas de transmisión mediante redes sociales, audio y video streaming.

Este trabajo de investigación realiza tres cortes metodológicos. El primero consistió en realizar un estudio estadístico de visitas a sitios blog por país que permitiera entender las estructuras de la red y la web, interpretando esta información con la estructura de cómo se da 
una forma particular de prácticas de comunicación. Como se observa en la Gráfica 1, la estadística de Google Trend. Inc, permite conocer las búsquedas focalizadas que se tienen en la red sobre temas selectos. Destacan para Latinoamérica los casos de México, El Salvador, Cuba, Guatemala, Costa Rica y Venezuela, obteniéndose información desde 2004 hasta 2016. El resultado nos muestra que entre los años 2006 y 2012 se observó una alta tendencia en el tráfico hacia las bitácoras electrónicas. La información referente a estos países coincida con un mayor crecimiento en su conexión a internet en la región en esos años, tras periodos de poco o nulo desarrollo de sus infraestructuras, dadas por monopolios o políticas públicas restrictivas en las telecomunicaciones.

Gráfica 1: Consulta en Google Trend. Inc, SOBRE BÚSQUEDA DE BLOGS LATINOAMERICANOS 2004-2016

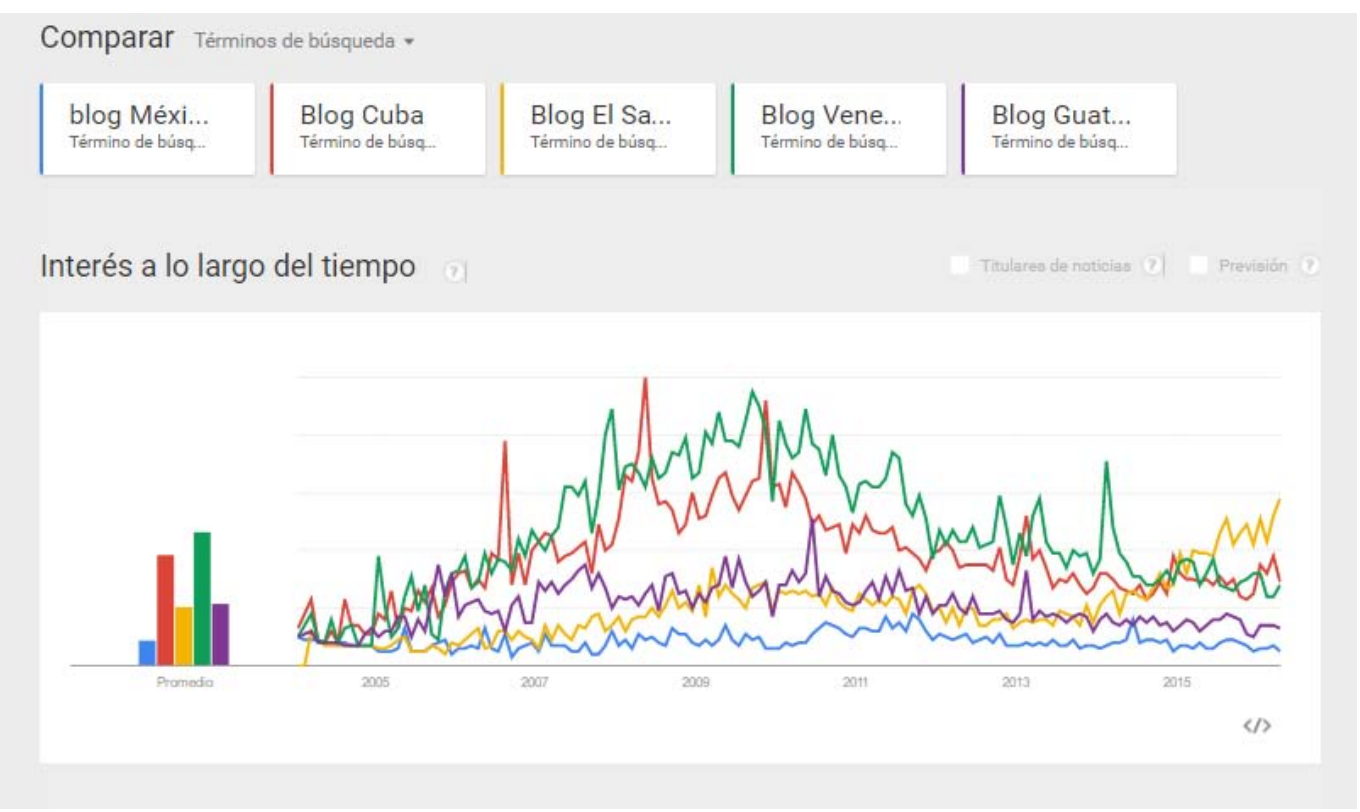

Fuente: $<$ https://www.google.com/trends/?hl $>$

El segundo corte consistió en la búsqueda de blogs que respondieran a cuatro temas específicos: tecnología, política, economía y relaciones humanas. Esta investigación identificó 364 sitios blogs citados en esas temáticas destacando los de mayor tráfico y seleccionando los relatos que producen un mejor discurso significativo sobre las relaciones sociotécnicas estudiadas. 
El tercer y último corte metodológico, sobre el que se centran los resultados del artículo, presenta el análisis de relatos y entrevistas de siete bloggers latinoamericanos. El perfil sociodemográfico de los bloggers seleccionados fue el siguiente: edad media de 36 años, estudios universitarios, cuentan con trabajo remunerado, viven en la capital de sus países, son las primeras generaciones que usan computadoras y son promotores del uso del blog.

Es claro entonces que la generación, el sexo, la residencia y la ocupación son sesgos presentes en la región seleccionada para el estudio caracterizada por brechas digitales y desigualdades que atraviesan la estructura social a lo largo de sus geografías. Es importante mencionar que los bloggers más influyentes se encuentran situados en la Generación "X" antes descrita y logran trascender a partir de otras habilidades como la comunicación y sistematización de experiencias humanas, económicas, políticas y una vehemente capacidad de reflexionar sus experiencias e interés de su generación aportando estilos de vida, revelando antagonismos políticos, denunciando inequidades sociales y culturales, proponiendo rutas de acceso a las redes, y resolviendo muchas de las dudas que planteaban la internación en estos medios.

\section{Resultados}

Desde su creación, la red de internet se organizó en un complejo entramado de hiperenlaces que posibilitan las interconexiones de muy diversos paisajes virtuales. Uno de los espacios que sobrevive aún al embate de las redes sociales es el blog que se articula de forma nodal en las esferas web.3 Dichos esquemas permiten conocer una tendencia hacia la especialización e interconexión con redes noticiosas, editoriales periodísticos en línea, canales de información y un sinnúmero de redes sociales como Facebook, Twitter o YouTube, constituyéndose en verdaderos nodos temáticos de comunicación con otras redes en las que se comparten temáticas, posicionamientos políticos, opciones de capacitación técnica o simplemente la opinión de personas que mediante relatos textuales constantes logran la atención de numerosos lectores. El análisis de esferas web como es el caso de los blogs ayuda a reconocer su función actual como nodo que mantiene una estructura social y comunicacional estable a partir de temáticas y editoriales que desarrollan la función de posicionar a quienes las escriben y propagan líneas editoriales con resonancias en las redes sociales, dan una estructura inmaterial, fugaz y en ocasiones inatrapable que caracteriza las tramas de hiperenlaces en el internet.

A partir del análisis de las esferas web, se enfatiza a continuación en la experiencia de siete bloggers que desde sus distintos contextos reflexionan en torno a la experiencia blog y 
las identidades narradas. Ellos cuentan con numerosos seguidores, notoriedad y relativo reconocimiento público en la esfera pública nacional y/o internacional.

Un primer ejemplo de autodefinición pertenece al salvadoreño Víctor, quien se identifica con el seudónimo "Alta hora de la noche". Él narra el muy personal acto de fundar su espacio blog en un país centroamericano.

Hace 1097 días escribí: "He decidido al fin iniciar mi blog como un modo de mantener me alejado de los malos pensamientos...". Probablemente no haya logrado mi objetivo ini cial, o es que éste ha cambiado. Hoy convivo con los pensamientos malos y buenos y, como siempre, los escribo. Y este espacio ha cambiado de cara varias veces, y los contenidos se han ido puliendo desde un comienzo medio incierto hasta quedar como un reflejo de mis reflexiones sobre la realidad en que vivo. Han ( sic) habido ratos en que he querido dejar de escribir posts y otros en que el blog se quedaba corto para todo lo que quería de cir. Y acá estoy ahora, a tres años y dos días de haber iniciado esta virtual aventura con ga nas de seguir hablando. Víctor

Alta hora de la noche. El Salvador. $<$ http://altahoradelanoche.blogspot.com> (Publicado: 2009, 8 Mayo)

En la mayoría de los relatos, los bloggers tratan de superar su contexto o una situación particular y, buscan entrar a otro nivel más favorable usando sus reflexiones en la red para conseguirlo. Lo hacen de forma pública para cientos o miles de lectores. En el caso de Víctor, con su sitio activo desde 2005, ganador del premio al Blog Solidario en 2008, más de 30 mil lectores en 2015 lo hacen un suceso emblemático en El Salvador.

Un hito del blog latinoamericano es Yoani Sánchez, que se caracteriza por ofrecer a sus lectores una identidad local desde la cotidianidad y una escritura transgresora que la hacen ser reconocida dentro y fuera de su nación como una referencia regional e internacional, cosa que pocos logran desde estas plataformas. Yoani ha sido la depositaria del emblema de la mujer que usa la tecnología para romper el control regulatorio que sostiene el Estado cubano alrededor del acceso y el uso de la red de internet. De hecho la política comunicacional basada en la socialización selectiva y controlada verticalmente, es un factor que constantemente la legitima y prestigia dadas sus críticas mordaces, disidencias ideológicas y actuar en nombre de una identidad deteriorada, underground, outsider. A ella se le ha reconocido un papel importante desde las redes fuera de Cuba, donde está la mayoría de sus lectores, mientras que al interior cuenta con pocos seguidores y algunos lectores que po- 
lemizan. En una de sus entrevistas disponibles en el sitio YouTube, ${ }^{3}$ Yoani se presenta a sí misma en los siguientes términos:

Mi nombre es Yoani Sánchez. Soy graduada en Filología, pero en realidad desde hace un año para acá me defino como blogger, pues tengo una bitácora en internet, que se llama "Generación Y", y tengo 32 años. Tener un blogger en Cuba es una aventura un poco loca, ¿no?, primero porque el nivel de conectividad de los cubanos es muy bajo. No podemos tener un acceso a internet desde casa, y entonces eso me obliga a hacer un montón de ma labares... casi prácticamente magia tengo que hacer para colocar un blog en internet.

Generación Y. Cuba. Entrevista $<$ https://www.youtube.com/watch?v=a31Lexa71wM>

(Publicado: 2010, 20 mayo)

Más allá de la dramatización de sus "malabares" y las solidaridades para lograr conexiones a internet, hace referencia inmediata a las condiciones precarias de conexión y las limitaciones de la infraestructura con la que se cuenta en Cuba para una amplia e inclusiva socialización de la cultura informática. El ambiente virtual con que ella y otros definen la blogosfera es complejo, si se considera su intervención en la resolución de problemas sistémicos, como lo son el cambio, la actualización y la innovación tecnológica, y el apoyo a quiénes tienen las condiciones menos favorables para una conexión estable a la red.

Los bloggers escriben de la existencia de una red humana conectada globalmente por elementos electrónicos en la que se intercambian experiencias en el ámbito sociotécnico. Dichos elementos permiten la conectividad física y funcional la cual establece flujos de información e intercambios de experiencias que pueden ser reflexionadas teóricamente para fortalecer la definición de una identidad como alteridad virtual, resolver la tensión ante una vehemente vulnerabilidad tecnológica (el control estatal, el de las empresas, y otros actores de poder) y explicar al paisaje blog como espacio de encuentros dados por la apropiación espacial y temporal de la tecnología y la producción textual de episodios sobresalientes sobre el mismo ámbito tecnológico. La épica crítica que ha pretendido desarrollar Yoani

\footnotetext{
${ }^{3}$ El desarrollo de Touchgraph permiten graficar esferas web para la sistematización de los procedimientos de representación visual de las redes, con fines descriptivos; la identificación de comunidades; la construcción de redes globales a partir de redes personales; el estudio de las estrategias con las que los actores individuales hacen uso de las redes complejas, y la monitorización del crecimiento de la red.
} 
Sánchez subraya un carácter alternativo ante censuras sociales, políticas y del mercado; de alguna manera, su línea editorial busca ir más allá de las restricciones o los bloqueos con pretensiones de liderar un movimiento más amplio dentro del conjunto diverso de la blogosfera cubana y fuera de ella.

Como el estornudo de una gripe deseada, la blogosfera alternativa cubana no deja de propagarse. Ya no se parece a ese páramo que mostraba ¿si acaso? unas pocas páginas con seudónimo en abril del 2007, cuando comencé con "Generación Y". He perdido la cuenta de cuánto somos ahora porque cada semana me entero que han nacido, al menos, dos nuevos espacios virtuales. El bloqueo de varias plataformas bloggers y los constantes ataques sólo han servido para que el virus de la opinión libre mute hacia formas más complicadas de callar. El ADN de la expresión ciudadana no cederá ante vacunas basadas en la intimidación y la difamación: terminará por infectar a todos.

Generación Y. Cuba. Entrevista. $<$ https://www.youtube.com/watch?v=a31Lexa7lwM $>$

(Publicado: 2010, 20 mayo)

El itinerario del blogger provee una identidad, ya que entre la experiencia vivida y la narración de la misma existe una relación que establece la filiación constitutiva. Al final el blog es un conjunto de experiencias contadas y, como dicen Santamarina y Marinas (1998): “... no hay identidad cultural que no sea contada..." (p. 57). La relación entre blogger, narración y reconocimiento de la identidad/alteridad se hace tangible en el pensamiento expresado mediante el lenguaje y el diálogo que constituye y transforma tanto al narrador como a su interlocutor en la red durante el hecho comunicativo.

Harold es un blogger costarricense que desde 2006 escribe con cualidades distintas a las de Yoani. Reconoce su inexperiencia y hace de ella una virtud para conjuntar adeptos a su blog. En un tono desenfadado le pide a sus lectores se sientan libres en su espacio y compartan con él cosas de la vida cotidiana, preferentemente banalidades, siento éste el gancho de su éxito en la red. El contacto que Harold hace con su audiencia es a partir de acciones jocosas, pero llenas de un sentido de la experiencia humana cotidiana.

Vivo en San José, Costa Rica y desde Agosto del 2006 empecé este blog [...]. Siempre intento buscar cosas interesantes o impresionantes para comentarlas, no quiere decir que sepa mucho de ellas, porque "sólo sé que nada sé", pero se pasa el rato. Sentite (sic) libre 
de decirme lo que piensas del blog, de darme consejos o críticas para poder mejorarlo. Si querés (sic) contactarme, mandarme chistes, opiniones, dudas, o propuestas de matrimonio (sólo mujeres por favor), no dudes de enviarlas que me encanta recibir sus opiniones. Pue den contactarme aquí.

Harold. Costa Rica. $<$ http://www.harolsblog.com>

(Publicado: 2006, 5 agosto)

Por su parte Hunnapuh relata la manera en que la comunidad blogger se reconoce a sí misma mediante sus escritos realizando un conocimiento mutuo mediante la lectura recíproca, la distinción regional, el reconocimiento generacional y la aceptación de las formas de pensar y actuar situándose en contextos ácidos y violentos en El Salvador. Una sociedad particularmente violenta en donde el análisis crítico en internet es una forma de actividad política con acuses de recibo y destinatarios.

Nos sumamos a la iniciativa de Juan Carlos, el autor del blog Sura'sWay, por favor dejen sus comentarios al respecto para que pueda recopilarlos y enviárselos o de alguna manera hacerle llegar el sentir de la población cibernética que de una u otra manera busca infor marse y opinar en los diferentes blogs salvadoreños. La blogosfera salvadoreña aunque grande y en constante crecimiento es abarcable todavía y creo que todos los aquí mencio nados y los otros que no pero que de alguna manera nos conocemos, nos leemos mutua mente cada vez que tenemos tiempo y visitamos los pocos periódicos electrónicos que están en la red, en mi caso aprovecho el medio día para revisar lo que los amigos blogueros dicen: desde los ocurrentes, iconoclastas pero consecuentes amigos del Trompudo, hasta los brillantes jóvenes de Campo Pagado, pasando revista con frecuencia a los amigos que tengo en el BlogRoll y a los blogs mencionados en este post que son auténticos referentes del pensar nacional. (Ya no leo periódico impreso e incluso mi primera revisión de las no ticias diarias la hago en los blogs antes que en los periódicos). 2009, el año más violento.

Hunnapuh. El Salvador.

$<$ http://hunna.org $>$

(Publicado: 2010, 25 marzo) 
Otra cualidad de la identidad se halla en la reflexividad que despliegan sobre su propia actividad. En algunos casos se trata de un verdadero autoanálisis y de la capacidad de proponer (contra) códigos éticos y normas de conducta ante un fenómeno determinado. En mayo de 2009, el guatemalteco Javier A. Roche propuso a la comunidad la observación de cinco normas, para dialogar alrededor del erróneo manejo financiero que hizo el gobierno guatemalteco y que llevó a la quiebra a su banca de desarrollo social y rural. No es gratuito que este tipo de llamado a la responsabilidad colectiva y la movilización social tenga eco en parte de la comunidad internet.

Algunos puntos que quiero compartir con la gente twittera y bloguera de Guatemala:

1. Todos somos responsables de lo que escribimos en internet, haya ley de pánico fi nanciero o no.

2. Si realmente quebrara Banrural, siendo éste uno de los bancos más grandes, habría una gran crisis financiera que sólo agravaría la situación. Si conocen a algún economista, pueden consultarle, no es así nomás. Si existen malos manejos allí, debe haber otras maneras de sanearlo.

3. Siempre se dice "es que el gobierno no entiende". Pero creo que esta vez - al menos la gente del gobierno que rastreó el mensaje de Twitter- sí que entiende que un simple mensaje de menos de 140 caracteres puede tener repercusión social.

4. Felicito a la gente que fue a apoyar a Torre de Tribunales a @jeanfer y los que dona ron para su fianza, porque demostraron que la idea de comunidad para ellos no es sólo de mensajes por internet y reuniones con pizza, shucos y risas, es algo más.

5. Hay un ambiente enardecido con el escándalo actual. No es hora de agarrarse a trompadas con los que no piensan como nosotros, ni de tratar de ser héroes. Es hora de exigir justicia, sí, pero siempre habrá que reflexionar sobre lo que decimos y hacemos, haya escándalo o no, haya crisis o no.

Javier Aroche. Guatemala.

$<$ http://javieraroce.com>

(Publicado: 2008, 19 mayo)

En la misma dimensión política, el mexicano Javier Treviño se reubica del ámbito amateur al profesional y destaca el limitado crecimiento del mundo de los blogs. En el caso de México eran poco más de 22 mil bitácoras las activas en el momento de su publicación. Javier explica que no es novedad el número tan bajo de bloggers en un país en donde sólo cinco de cada cien personas tiene conexión fija a internet. Dos temas importantes tratan en su relato. 
Primero, que la participación queda supeditada a la infraestructura. Segundo, la aparición del ciberespacio como uno de los campos en donde la clase política y los ciudadanos pueden librar batallas. Las dos son hipótesis difíciles de derrumbar, sobre todo en los dos últimos procesos postelectorales, en donde México muda sus escenarios de debate a las calles y espacios en la red de internet y deja de aparecer en los medios tradicionales de comunicación y sitios de legislación.

Hasta en un país tan resistente al cambio como el nuestro, los nuevos "medios sociales" están creciendo. Con base en cifras de la red social bitacoras.com, el blog Rienzie calcula que en México hay más de 22,600 bitácoras personales actualizadas en línea, mientras que el directorio blogsmexico.com incluye casi 11,000. La falta de avances en materia de conectividad en nuestro país ha hecho que su alcance siga siendo limitado. Según la Asocia ción Mexicana de Internet, las cuentas de banda ancha crecieron más de 48\% entre 2006 y 2007, llegando a cerca de cuatro millones. Por su parte, la OCDE considera que a media dos del año pasado México tenía menos de 5 suscriptores a servicios de Internet de banda ancha por cada 100 habitantes

Javier Trevino. México. $<$ http://javiertrevino.blogspot.mx $>$ (Publicado: 2008, 26 marzo)

Juliana Boesner en Venezuela subraya factores no epistémicos como las expectativas profesionales, presiones económicas, disponibilidades técnico-instrumentales, convicciones y valores personales, para realizar su bitácora personal y devenir en menos de un año a su actual profesión, la de una blogger con más de 10 sitios, muchos de ellos colectivos, patrocinados por secretarías de estado, casas editoriales y fundaciones en donde ella ocupa el puesto de coordinadora editorial.

Bueno, eso fue en octubre de 2005. En diciembre del 2006 el equipo de Web Blogs de España me ofrece trabajar para ellos en el blog Papel en Blanco, que es un blog literario, un blog colectivo, que pertenece en este caso a una compañía de blogs que tiene pues muchos otros blogs, Gembeta... Entonces comienzo a trabajar con ellos y a los meses me ofrecen que yo sea la coordinadora editorial de este blog, lo cual significaba pues guiar un 
poco, dar las políticas editoriales, verificar que siguieran las líneas editoriales de la com pañía, y también allí he seguido trabajando con ellos en un formato distinto al formato del blog personal, digamos, ¿no? Ese fue, digamos, el comienzo.

Juliana Boesner. Venezuela.

$<\mathrm{http}: / /$ www.ciberescrituras.com/>

(Entrevista por Skype: 2012, 5 noviembre)

Es claro señalar que la identidad de quien decide ser blogger se conforma con apoyo de una extensa comunidad de técnicos, lectores, miembros de otras comunidades, industrias de la comunicación e información, gobiernos y organizaciones que apoyan el desarrollo de internet. Entre aciertos y errores desarrollan habilidades técnicas, las cuales les obligan a actualizarse en el manejo de programas y uso de equipos de cómputo. Se constituyen en una comunidad de aprendizaje y creación.

Los ideales blogger respecto a la libertad, la solidaridad, la adhesión y el respeto en la convivencia en la red de internet han generado adeptos por todo el mundo. Seguir los pasos de uno de ellos no es cuestión de solidaridad generacional, empatía o simple moda. Para Octavo Cerco de Cuba, es una cuestión de madurez intelectual, en donde se es capaz de trascender el ámbito privado $\mathrm{y}$, mediante figuras literarias, llevar a los lectores a conocer a través de su visión personal una faceta que explica alguno de los contextos nacionales de los países desde donde escriben. Su sitio nos muestra lo que considera desde su punto de vista actos de injusticia cometidos por el Estado, el abuso de poder y la restricción a las libertades, todo ello mediado por niveles de censura y autocensura que actualizan en los blogs luchas por "...la hegemonía cultural en razón de los ejes de desigualdad nacional, racial, clasista, religioso y de género" (Basail, 2002, p. 251), así como “...autocensura, el silencio voluntario y rencoroso, escepticismo, reduciendo el campo perceptivo respecto a la realidad social vivida y, al mismo tiempo, promoviendo la crítica social en espacios públicos y privados donde la discursividad dejaba notoriamente reducida las pretensiones de recursividad de aquélla [la censura]" (ibid).

Sentí ganas de contar las cosas a mí alrededor, de compartir el absurdo total con alguien. Yoani Sánchez me explicó lo que era un blog, publicó ella misma en "Generación Y” mi primer post y me ayudó en toda la parte técnica, hasta le tiró una foto a unos huevos para mi primera entrada en Octavo Cerco, sin ella quizás nunca hubiera descubierto la posibilidad de tener una bitácora. 
Para darle un poco de coherencia a esta especie de declaración de principios Octavo Cerco que estoy haciendo, lo ilustraré con una pequeña historia - que no importa si es real o no porque no es una noticia, es un ejemplo-: imagine que usted tiene un blog en el que escribe sobre el mundo que le rodea, y que un día un lector le toca a la puerta y le dice: Vine a decirte que quizás hoy me arreste la Seguridad del Estado, pero por favor, no vayas a publicarlo.

Es así que he decidido poner los puntos sobre las íes:

- Hago este blog sola, bajo mi absoluta responsabilidad como es lógico.

- Es una visión personal y subjetiva de la manera en que veo y vivo mi país.

- Los actos de injusticia, de abuso de poder y de restricciones sobre las libertades de los individuos, me siento en el deber - conmigo misma - de publicarlos y comentarlos desde mi óptica.

- No existe razón externa que pueda hacerme dudar de dar una opinión, de criticar lo que considero incorrecto, o de alabar lo que me gusta.

- No me debo a nadie y la censura contra la que lucho día a día es la autocensura (que es muy peligrosa).

— La información no pertenece a nadie, todos tenemos derecho a ella y por eso abogo.

Octavo Cerco. Cuba.

$<$ http://octavocerco.blogspot.com>

(Publicado: 2008, 8 julio)

La disciplina para mantener un blog, no siempre se consigue. Menos aún la búsqueda de sentido que refleje el para qué de la inversión de tiempo, energías y empeño al oficio de la escritura. De la misma manera el blogger duda, pero también se entrega al placer de "decir, escribir y opinar" sin límites ni censuras. Sin duda el texto en la red aspira a trascender, a contar con una estructura sólida, hasta que llega la opinión de los lectores del blog y lo que pareciera formalmente estructurado, ordenado y racionalmente pensado, presenta fisuras en los contenidos y hace que el autor tenga reacciones poco predecibles ante la experiencia de la interlocución.

La investigación y la evidencia permiten destacar que:

1. La producción textual de los bloggers conlleva un estilo, ritmo, intencionalidad y posicionamiento ideológico, que en conjunto constituyen elementos para caracterizar a quienes producen blogs. Lo anterior se complementa con elementos identitarios, características sociodemográficas y adscripciones socioculturales que exponen en sus 
perfiles y desarrollan en sus contenidos textuales mejor conocidos como post, los cuales representan el origen y destino de la interacción que se establece entre quien escribe y el lector. Cabe mencionar que las cualidades que destacamos en los bloggers latinoamericanos estudiados son referentes a: i) el respeto a la convivencia y la diversidad de opiniones, ii) la capacidad para establecer conexiones a partir de sus procesos históricos, iii) el uso del español en un ambiente web plagado anglicismos que domina el lenguaje técnico operativo del internet, iv) el adaptar sistemas de alfabetización tecnológica que permitan bloguear más y mejor en español y con ello contrarrestar, en lo posible, a los emporios editoriales que dominan a internet desde su inicio. El proceso anteriormente descrito vigoriza una comunidad política imaginada que es “...imaginada porque aun los miembros de la nación más pequeña no conocerán jamás a la mayoría de sus compatriotas, no los verán ni oirán siquiera hablar de ellos, pero en la mente de cada uno vive la imagen de su comunión" (Anderson, 1993, p. 3). Sin duda, esta definición de comunidad imaginada es la que fortalece la red de bloggers por toda Latinoamérica, la cual amalgama y fomenta la imagen de comunión.

2. La innovación y funcionamiento técnico de los portales web, logró posicionar a principios del siglo XXI a un porcentaje nada despreciable de usuarios de la red de internet a escala global. En un inicio de la web, en los años ochenta, las corporaciones trataron de marcar el ritmo y el contenido a los portales web. Sin embargo, con la llegada de blog a finales de los años noventa se rompieron algunas barreras. En la web ocurrió un fenómeno poco predecible: el blog, su innovadora tecnología y el gestor de las bitácoras lograron poner al alcance de un público estratégico una opción literaria en los contenidos que conforman y pueden pensarse como un producto cultural, el cual fue enriqueciendo las experiencias temporales y espaciales contemporáneas y la discursividad sobre sus cambios.

Los blogs lograron en pocos años contribuir a la desestructuración del dominio de las grandes editoriales de los siglos XIX y XX, y de las influyentes corporaciones informativas que desde los diarios impresos dominaron durante más de cinco siglos la opinión publicada y jugaron fuertemente en la constitución de las realidades política, económica y social de las sociedades latinoamericanas. Particularmente forjó a un nuevo sujeto social, el blogger, capaz de ver, sentir y escribir frente a una plataforma de comunicación tecnológica para una comunidad virtual y real. Hacer lo anterior, provocó niveles de reflexión alternativa y gestión autónoma en cientos de individuos, que frente a pantallas y teclados nunca dudaron en expresar de manera textual su experiencia de vida, superando límites ortográficos, lingüísticos e idiomáticos. En la actualidad, el escenario comunicativo es más plural y alternativo porque miles de latinoamericanos logran posicionar un texto suyo en la red, y con ello emitir periódicamente un posicionamiento político, económico, tecnológico o de cualquier otro tema. 
3. La identidad blog se configura con diferentes cualidades electivas. Una de ellas restringida a lo que son como sujetos, hombres y mujeres que “...deben usar su propios medios e inteligencia para elegir su identidad" (Bauman, 2005, p. 23), y otra, que les dice que no tienen una opción diferente a la impuesta por algún modelo de blogger exitoso y reconocido. Esta tensión en la elección de un modelo u otro se da en un medio tan permisible como lo es la web, en donde se vive la apariencia que en este paisaje tecnológico, como en ningún otro, el individuo posee la capacidad de tomar y dejar, de usar y prescindir, de presentar y adscribir una identidad cambiante de acuerdo a su interés y conveniencia. Sin embargo frente a la pérdida inevitable de sentido, o la posible imposición de identidades por parte de una que oferta e impone identidades, tal y como lo hacen quienes ofertan modelos de teléfonos celulares a un mercado ávido de consumo, el paisaje tecnológico blog “...se ha dado a ofrecer plena libertad a las identidades y ahora son los hombres y mujeres concretos quienes tienen que cazarlas al vuelo, usando sus propios medios e inteligencia" (Bauman, 2005, p. 68). No podemos ignorar las cualidades que el ambiente web ofrece al interlocutor en donde los colectivos son súbitamente móviles que evolucionan rápidamente, buscan construirse e intentan dar coherencia a la vida, aunque sea por algunos instantes y no mucho más. Se reconoce el esfuerzo de los bloggers latinoamericanos por discutir las diferentes cualidades de su identidad, principalmente en el reconocimiento del quehacer de otros bloggers, su actuar dentro de la red en la elaboración de mundos (narrativos) y personalidades (virtuales) que se desarrollan a través de múltiples medios y plataformas, integrando experiencias, muchas de las cuales son interactivas. A diferencia de otros momentos de la narrativa, la del blog, es bidireccional o multidireccional debido a que las técnicas que se utilizan así lo permiten. Por tanto, pareciera que la identidad del blogger se va redefiniendo a partir de la propia actividad e interactividad con los demás en internet con los que el presente se convierte en experiencia colectiva. Por ejemplo, el efecto de la traducción intersemiótica en la que una misma experiencia textual se reproduce en distintos medios, o la traducción de lenguaje por medio de traductores en la web, permite que la narrativa tenga una inmersión digital, social y emocional nunca antes valorada. La interpretación del texto acentúa uno u otro rasgo de la identidad del blogger, debido a que sus relatos son reconocidos, interpretados, criticados, satirizados y censurados a través de las réplicas y glosas de un público lector/conectado situado en contextos de recepción siempre desiguales y asimétricos.

\section{Conclusiones}

Al final del siglo XX se consolidaron investigaciones que versaron sobre la experiencia humana en la red de internet. Espacio en donde “...han aparecido formas discursivas audaces, que rompen con el cierre textual, invitaciones a la libertad, al juego, la creatividad, todo es 
posible, la mente es un explorador inagotable" (Galindo, 2006, p. 178). En particular, en la primera década del siglo XXI en internet se promovió el vértigo sobre el movimiento y la velocidad de la información, en donde el individuo enfrentó, entre otros muchos retos, el de salvar la brecha digital. Lo anterior es consecuencia de un largo proceso tecnológico, resultado de descubrimientos e innovaciones en los campos de la mecánica, electrónica, telemática y en la ejecución de las políticas públicas que dieron pesos diferenciados al estado, al mercado y la sociedad en la provisión y uso de bienes y servicios telecomunicacionales con lógicas y procesos desiguales. Por tanto ha devenido una necesidad de estudiar más un campo metodológico-tecnológico que promueva “...una capacidad de síntesis de conocimiento sistemático, la construcción de tipologías, y pensar a la información como un constructo y guía de acción” (Galindo, 2006, p. 219).

Los nuevos retos de investigación sobre tecnología permiten plantear las diversas rutas por donde los individuos van construyendo los procesos sociotecnológicos y éstos van modificando las dinámicas humanas, hasta el punto de creer que a partir de las mismas serán fundados "la verdadera religión", "la nueva arena política", "el más grande escaparate comercial" o "el mejor medio para la comunicación". En nuestra época y en la región latinoamericana la tecnología de internet se constituye en un reto para el entendimiento de quienes usamos internet y de nuestro mundo, en donde los fenómenos que suceden en la red de internet pasan a ser parte de la tecnología de comunicación y se fortalecen sistemáticamente en un sistema acotado, en donde cohabitan muchos humanos, considerando al resto del mundo como su entorno. Se habla entonces de encontrar posibilidades en el análisis, la reflexión y las teorizaciones de las experiencias humanas relatadas en miles de blogs de manera autónoma, gratuita, libre, instantánea y reflexiva, desde Latinoamérica, desde diferentes contextos culturales y perfiles sociodemográficos. Ello hace que la reflexión textual y mediática que el blog ofrece, sea única, con cualidades significativas, sociológicamente hablando, para la investigación social de la experiencia contemporánea de la humanidad.

El blog, desde su emergencia a principios de siglo y su actual rol secundario o superpuesto, aporta a la comprensión de los procesos de atribución de significados en la constitución simbólica de la realidad social latinoamericana por medio de relaciones tecnológicas en internet y trayectorias biográficas individuales y colectivas. Por ello, se aprecia y valora la experiencia aprendida en la producción del dato, que se apoyó con un método etnometodológico, enfocado a conjuntar las maneras en que las personas comparten (en el sentido comunicativo) los hechos, procesos y acontecimientos sociales, construyendo una práctica interpretativa en donde se conjuntaron “...los procedimientos, condiciones y re- 
cursos a través de los cuales la realidad es aprehendida, entendida, organizada y llevada a la vida cotidiana" (Wolf, 1994, p. 13).

En medio de la heterogeneidad estructural y de las incertidumbres en la vida política y económica de los países latinoamericanos, existen lugares en lo intrincado de la red donde el hablante y el oyente tienen contacto, discrepan y acuerdan a partir de imágenes lingüísticas del mundo cotidiano. Con experimentadores que de forma creativa dan cuenta de y cuentan sus realidades sin pretender agotarlas, se reconstituyen epistemes mediáticas donde se expresan de manera muy creativa tramas discursivas disímiles que permiten intercambiar reflexiones sobre valores y normas de distintas prácticas culturales e interactuar por medio de un conjunto de tecnologías. Sin duda, el blog representa un espacio singular con condiciones de comunicabilidad donde sus hacedores, los blogueros, figuran como creativos culturales cuya huella advierte sobre la dinámica de los cambios históricos, la emergencia de una conciencia crítica y las tensiones entre estilos culturales y visiones del mundo a inicios del siglo XXI. 


\section{Referencias}

Anderson, B. (1993). Comunidades Imaginadas. Buenos Aires: Fondo de Cultura Económica.

Anjewierden, A., Brussee, R., y Efimova, L. (2004). Shared conceptualisations in weblogs. In BlogTalks 2.0: The European Conference on Weblogs (pp. 110-138). Thomas N. Burg.

Basail, A. (2002). Estilo de Época, Comunicación Política y Cultura Impresa. Procesos culturales y cambios sociales en Cuba (1878-1895). Trabajo de grado, Doctorado en Ciencias Sociales, Universidad del País Vasco, Bilbao-La Habana.

Bauman, Z. (2005). Ética posmoderna. Buenos Aires: Siglo XXI.

CAYzer, S. (2004). Semantic blogging and decentralized knowledge management. Communications of the ACM, 47(12), 47-52.

Galindo, C. (2006). Cibercultura. Un mundo emergente y una nueva mirada. México: CONACULTA-IMC.

Garfinkel, H. (2006). Estudios en Etnometodología. Barcelona: Anthropos.

Giménez, G. (2015). Cambio cultural y “creativos culturales”, en Argueta, Arturo y Peimbert Frías, G. A., La ruptura de las fronteras imaginarias o de la multi a la transdisciplina. México: CRIM-UNAM/Siglo XXI, pp 142-159.

Hsu, C. L., y Lin, J. C. C. (2008). Acceptance of blog usage: The roles of technology acceptance, social influence and knowledge sharing motivation. Information\&management, 45(1), 65-74.

Lash, S. (2005). Critica de la información. Buenos Aires: Amorrortu.

NArdi, B. (2004) Blogging as Social Activity, or Wold You Let 900 million people read your diary. Chicago: Paper conference on Computer Supported Cooperative Work.

Castells, M. (1999). La Sociedad Red: La era de la información. México: Siglo XXI..

Santamarina. C. y Marinas, J. (2007). Metodología de la Investigación III. Notas del curso en el Doctorado México: Ciencias Sociales y Humanísticas. CESMECA-UNICACH.

Schittine, D. (2004). Blog: comunicação e escrita intima na internet. Brasil: Editora Record.

Sullivan, A. (2010, junio). When Bloggers Wed [en línea]. Disponible en: $<$ http://dish.andrewsullivan.com/2010/06/14/when-bloggers-marry/> [2015, 5 de junio]. 
Thomas, H. (2009). Tecnologias para inclusão social e políticas públicas na América Latina. Documento presentado en el I Encuentro internacional culturas científicas y alternativas tecnológicas, Buenos Aires.

Wolf, M. (1994). Sociología de la vida cotidiana. Madrid: Cátedra.

Wrede, O. (2004). "Weblogs and Discourse - Weblogs as a transformational technology for higher education and academic research", en Burg, T.N. BlogTalks, 217-237. Viena: Zentrum für Wissenschaftliche Forschung und Dienstleistung. 